\title{
Argument or Explanation: Who is to Decide?
}

\section{Michel Dufour}

Institut de la communication et des médias (ICM)

Université Sorbonne Nouvelle - Paris 3

Michel.Dufour@univ-paris3.fr

\begin{abstract}
Granting that explanations that answer a why-question, and arguments, are the products of two species of the activity of reasongiving, do they make an exclusive and exhaustive classification? The orthodox distinction between explanation and argument is based on the status of their conclusion: is it accepted or not? However, this view faces some tough cases, which are discussed. Most of the criteria used to distinguish argument and explanation according to the orthodox view cause tough cases to proliferate and hardly accommodate common communicative situations. This suggests that the orthodox distinction is not satisfactory.
\end{abstract}

Résumé : Une fois concédé que les explications répondant à une question "Pourquoi?" et les arguments sont deux espèces de l'acte consistant à fournir des raisons, l'article demande si elles en forment une classification exclusive et exhaustive. La distinction orthodoxe entre une explication et un argument repose sur le statut de sa conclusion : est-elle acceptée ou non ? Cette distinction fait cependant face à des cas embarrassants que l'on va discuter. La plupart des critères utilisés pour distinguer argument et explication dans le respect de cette orthodoxie induisent une prolifération de cas embarrassants et peinent à rendre compte de situations communicationnelles banales. Ceci invite à penser que la distinction orthodoxe n'est pas satisfaisante.

Keywords: argument, explanation, reasons, evidential reasons, explanatory reasons, epistemic asymmetry.

\section{Introduction}

For the purposes of this study, I will assume that argument and explanation are two species of the same genus, which I will call a rationale, understood as the public manifestation of the activity of putting reasons forward. ${ }^{1}$ It typically results in propositions

\footnotetext{
${ }^{1}$ Some people may consider that a rationale takes place in the mind and arguments take place in conversations. This is not the distinction I make between rationale and argument. In this paper, a rationale is a piece of reasoning that can be a communicative event. I use the word rationale in order not to use argument as a generic term but only as a specific term, so that some room is left for something that is a rationale but is not an argument. The candidate I am interested in is explanation.
} 
offered for another proposition, which I will call the conclusion. ${ }^{2}$ Do arguments and explanations constitute an exclusive and exhaustive classification of rationales? This vexed question is the topic of this paper.

Two paradigmatic practical situations inspire the explanation/argument distinction. The first one is explanation-seeking: Some people agree about the truth of a proposition $p$ and then try to answer "Why- $p$ ?". Tom's car does not start. Why? A possible explanation is that the battery is dead. The second paradigmatic situation is controversy. Does God exist? You propose your reasons; I propose mine. A distinction, that I call "orthodox", links explanation with the first situation, and argument with the second. Can any rationale that is put forward be reduced to only one or the other of these two prototypical situations? Can it be both an argument and an explanation? Can it be neither?

Both theses - exclusivity and exhaustivity - depend on the very definition of argument and explanation. For some authors, for instance, Sinnott-Armstrong and Fogelin (2010, p. 3), an argument amounts to what I have called a rationale: They consider that giving reasons for a proposition is a necessary and sufficient condition to produce an argument. An explanation is then a kind of argument or a kind of use of argument. ${ }^{4}$ Other authors have a more restricted concept of argument that can leave room for rationales that are not arguments. In this case, the four expected answers to the question "Is this rationale an argument or an explanation" are: it is an argument, it is an explanation, it is both, it is neither of them. The third one challenges the exclusivity thesis; the fourth the exhaustivity one. The exclusivity thesisno explanation is an argument and no argument is an explanation-has been the most widely discussed.

Before going further, let us stress two points about explanation. First, it is a generic term that covers several varieties that can be roughly classified according to the kind of question they answer (how? what? why?...). Not all explanations are subject to my question. Only an explanation that proposes a reason of Tom's trouble with his car has the required logical structure to be involved in this debate. From now on, I will deal only with

\footnotetext{
2 I leave aside the possibility that a rationale has several conclusions.

3 It seems to be orthodox at least among many people interested in argumentation theory. In some other places it is not orthodox at all. In this paper, I am interested in the world of argumentation theory.

4 For a discussion of a possible classification of argument, see, for instance, Blair (2004).
} 
this kind of explanation, namely explanations that are or can be seen as answers to a why-question. Second, to say, like van Fraassen, that an explanation is an answer to a why-question (1980, p. 126) may not be sufficient: some authors claim that other conditions are required, for instance, to provide understanding or to state a causal relation (Salmon 1978, 1984, 1989; Kitcher 1989; Potochnik 2010). Yet in the debate on the distinction between argument and explanation, to answer a whyquestion is a necessary condition for a rationale to be an explanation, and it is a necessary and sufficient condition if this question is about a proposition that is not controversial. I will discuss the argument/explanation distinction only from this minimal view on explanation, which seems to have been inherited from logical positivism and has become orthodox in many critical thinking books. The discussion would be quite different if other conditions were required in addition to answering a whyquestion. The main aim of this paper is to show the issues that result from the orthodox distinction between argument and explanation based on this minimal view. No alternative approach of explanation will be discussed, let alone elaborated, in this paper.

\section{Tough cases}

In Reasons why arguments and explanations are different, Govier (1987) discusses some cases that Thomas called "tough cases" because he saw them as challenges to the exclusivity thesis. The possibility of an overlap between argument and explanation presupposes that their definitions were not worked out to avoid it. On the other hand, if an overlap is possible but some arguments are not explanations and some explanations are not arguments, then neither of these two subsets of rationale is included in the other. Govier thinks that this is the case because of what she calls the "pragmatic asymmetry" between argument and explanation, which I will discuss later.

What makes a case tough? Thomas's examples are short fragments (typically a few lines) coming from books. Each text provides enough information to acknowledge that it reports a rationale, but not enough to decide if it is an argument or an explanation. Both Thomas and Govier seem to grant the exhaustivity thesis because they do not consider the possibility that a rationale is neither an argument nor an explanation.

As far as I know, no attention has been paid to the fact that these tough cases come from written documents. Thus, they are 
conveyed through a slow communication medium that can reach an unforeseen audience and that usually offers no possibility of reply. They do not appear during a lively dialogue where, for instance, a participant would wonder "Do I argue or explain?" or would be embarrassed by someone asking "Do you explain or argue?" Thomas's cases are tough because it is difficult to answer a third person question: "Does the author argue or explain?" In a face-to-face dialogue, an easy solution would be to ask the person who puts forward the rationale. However, this presupposes that she knows what she does. Does she? The answer may not be that simple. "She explains, because she says that's what she is doing" could even be suspected to be a fallacious ad verecundiam rationale. Hence my question: "Who is to decide if a rationale is an argument or an explanation?" This kind of tough case is likely to proliferate as long as no answer is given, and I intend to show that, even when you get one, it is unconvincing, if not arbitrary.

Govier stresses that the distinction she makes between argument and explanation has pedagogical importance, but is difficult to grasp for students who are not trained in argumentation theory. ${ }^{5}$ This confirms that folk opinions on this topic are not reliable, perhaps less because they would sometimes be false than because the distinction is not clear or familiar to students. Accordingly, they may hesitate. So, on what grounds is this distinction made by theorists? Should their theoretical definitions nevertheless first try to rely on folk concepts or intuitions, and then accommodate some theoretical preferences? If folk opinions were clear but change from place to place or from time to time, theoretical definitions based on them would be likely to change too. This may be no problem, but a minimal virtue of a theoretical distinction is that it does not face a host of tough cases. Of course, you could say that the trouble with Thomas's examples is not a consequence of a conceptual deficiency, but simply that we lack some of the information necessary to solve the problem. This situation is quite common, and this could be a reason why students find the distinction hard to grasp. For example, in a booklet introducing proteins to primary school children, I read: "In a crystal, proteins are all concentrated in the same direction; therefore they all send the same signal to the detector of the synchrotron". Argument? Explanation? I identify a rationale, but it is a tough case for me, because I have no opinion about the truth of the two propositions. Even if I grant that

\footnotetext{
${ }^{5}$ I confirm that this distinction is difficult for my own students, who are not English speakers.
} 
argument and explanation are two distinct proper subsets ${ }^{6}$ of rationale, in this particular case I cannot make a decision between them. It is not certain that it challenges the exclusivity or the exhaustivity thesis, but, in any case, it reminds us that analysts are not omnipotent. Beyond this kind of difficulty, I contend that even with the relevant information the orthodox distinction between argument and explanation will face many embarrassing cases, unless it makes a debatable decision.

\section{Ways of distinguishing argument and explanation}

In his critical discussion of the argument/explanation distinction, McKeon identifies two rationales for distinguishing them: structural and pragmatic. He stresses that both use the same dialectical strategy: An argument is defined in a way that forbids that it is an explanation. It seems to me that this is possible because both depend on the same principle, expressed differently.

The pragmatic view is based on the consideration of the purpose of the rationale. McKeon writes: "From an analysis of the dialectical contexts in which arguments and explanations are given a general conception of the purpose(s) of an argument is derived that excludes the purpose(s) served by explanation" (2013, p. 292). The way this conception is "derived" from a contextual dialectical analysis needs to be clarified. When you read the two authors discussed by McKeon-Johnson and Pintoyou see that the purpose(s) of an argument is set before any theoretical (re)definition. ${ }^{7}$

Johnson's definition is framed by a specific purpose, derived from a local cultural practice: "The practice of argumentation is a rich intellectual practice that exists in some, but not all, cultures. It exists in North American culture but not all other cultures" (2000, p. 155). What happens in this culture? As shown by the very ambiguity of the English word "argument", "...the practice of argumentation presupposes a background of controversy" (p. 160). So, Johnson's concept of argument is empirically rooted in the local practice of controversy and in the strong association, in English, between the word "argument" and the practice of controversy. I previously asked whether a theoretical taxonomy should be based on folk taxonomy. Johnson's implicit answer seems to be "yes". His distinction between argument and explanation is not derived from general abstract

\footnotetext{
${ }^{6} \mathrm{~A}$ proper subset of a set is a (non-empty) part that differs from this set.

${ }^{7}$ We will see further that Hamblin even speaks of an a priori attitude.
} 
considerations, but from preliminary local observations. As McKeon rightly points out, Johnson's definition of argument also clearly rules out explanations. Here, an ancillary addressee gets in: "Supposing that the hearer already grants its truth [the truth of the conclusion of the rationale], the reasoner is offering an explanation why" (2000, p. 147). Johnson holds a version of the orthodox view: an explanation presupposes an agreement about the conclusion of the rationale, whereas an argument presupposes a controversy or at least a divergence of opinions. The important point is that the distinction between argument and explanation is based only on the status of the conclusion of the rationale. This suffices to decide whether the rationale is an explanation or not. For Johnson, its conclusion does not even need to be true. It suffices that the arguer supposes that the addressee grants it, as it is likely that the arguer does. The distinction is then arguer-centered, because it is based on her supposition that the other already shares her view that the conclusion is true. This supposition may be true, but it may also be false.

Pinto's concept of argument too is open to the other. For him, an argument provides reasons that are invitations for doing or not doing something "in an extremely broad sense of 'doing' in which believing, doubting, presuming, desiring, hoping, fearing, intending (and not just performing actions) can all be said to be things that we 'do' " (2010, p. 230). In a footnote, he adds: "In an explanation, this is not the case". Assuming that an explanation can be seen as an invitation for understanding, ${ }^{8}$ McKeon asks why offering reasons could not be an invitation to understand. I share his puzzlement and even if I betray my initial commitment not to speak of understanding, I will add that there are spongers: You may understand without being invited to do it.

The question is all the more pressing since Pinto claims that "arguers need not intend any effect beyond that of making it manifest to their hearers that there is reason for doing some particular thing" (p. 229) and that the effect produced may differ from the one intended by the arguer. Effects that Pinto calls oblique are possible. Thus, the addressee is not bound by the intentions or the representations of the arguer. This makes McKeon's point sharper: why couldn't understanding be at least an oblique effect, for instance a sponging effect? Yet Pinto holds that an explanation differs from an argument. "Very often when I give you reasons for me to do something, I am explaining to

\footnotetext{
8 This presumes that an explanation is more than an answer to a why-
} question. 
you or, in other cases attempting to justify what I did or why I am about to do that thing". When is there explanation rather than argument? Pinto's position is not very clear for me, but the same idea as is found in Johnson's account seems to be at work: you explain when the topic is not controversial, otherwise you argue. How do you know that a proposition is not controversial? Different authors opt for different reasons: it is true, or certain, or known, or taken for granted, or accepted. In Pinto's case, what he did or is about to do is not controversial for him. So, his view, too, is arguer-centered.

Controversial or not, this is also the ground of the rationale that McKeon calls structural: "The premises of an argument are offered in support of its conclusion, but the explanans of an explanation are not offered in support of its explanandum" (2013, p. 284). Here, the meaning of "support" may seem unclear if you compare with Johnson's opinion: "I offer reasons in support when I explain, ${ }^{9}$ 'The reason that your car won't start is that you have a dead battery, and also the starter is defective"" (2000, p. 147). Yet, the main idea is clear: Hempel states it by means of why-questions and truth. "Why is it the case that $p$ ?' is an explanation-seeking question that asks for an explanation whose conclusion, the explanandum $p$ is true. 'Why should it be believed that $p$ ?' is a reason-seeking question expecting evidential reasons for its conclusion $p$ " (1965, p. 334). McKeon's point is now clear: In an argument, the conclusion needs some support, whereas in an explanation, it does not. Fine, but who is to decide what is in need of support? We are often asked to support a view that is obvious for us. I hold Pythagoras's theorem to be an eternal truth, but my son can't believe it. He says that such a wonderful geometrical property would be a miracle. Is the classical proof I use to convince him an argument or an explanation? For Johnson, it should be an argument; ${ }^{10}$ for Pinto, it seems to be an explanation. Note that this tough case is different from

9 The italics are mine. There is a nice difference between Johnson's and Hempel's positions. Johnson can explain a future event. For Hempel (1965, pp. 366-376), you explain only a fact, event, or state of affairs, but you don't explain a future event. A future event is uncertain, so you can only predict it by means of the same argument (or, rather, the same premises). (Note that Hempel has a "broad" concept of argument: For him, an "argument" is what I call here a "rationale"). The possibility for the same argument to be both an explanation and a rationale supporting a future, or past, event is the famous symmetry thesis, which has been (is?) a vexing question in the philosophy of science. See Salmon (1989) for a good overview.

${ }^{10}$ I say "it should" because Johnson holds that a mathematical proof is not an argument. It lacks what he calls the "dialectical tier". See Johnson (2000, pp. 231-232) and Dufour (2013). 
Thomas's examples, because no relevant information is missing about the epistemic and pragmatic context.

I have said that two paradigmatic practical situations inspire the explanation/argument distinction. One is explanationseeking. Johnson's friend's car does not or will not start. Why? The battery is dead or, perhaps, the starter is defective. The other is controversy. Does God exist? You say yes, I say no, Gina doubts, Paul has no opinion. You propose your reasons, I propose mine, Gina hers (she is not convinced by our reasons), Paul listens. The orthodox view links explanation with the first situation, and argument with the second. Is there any reason to believe that any use of a rationale can be reduced to only one or the other of these two prototypical situations? I doubt it, but agree with Govier that tough cases do not make "the distinction between justificatory argument and explanation philosophically and epistemically dispensable" (Govier, p 175). I go further. The two paradigmatic situations that are associated with argument and explanation are quite common; hence, students should easily acknowledge that they are different and typical. However, I contend that the use of rationales spreads beyond these two paradigmatic situations, so that the exhaustivity thesis is false if argument and explanation are modeled on them.

You could argue: "People either agree or disagree, don't they? Therefore, the reasons they put forward are either evidential (when they disagree) or explanatory (when they agree)". However, there are people who neither agree nor disagree. Like Paul, they have no opinion at all about the trouble of Johnson's friend with his car, and others, like Gina, hesitate or are not certain. Your objection also presupposes that any process of reason giving fits into a face-to-face dialectical model. A consequence of this presumption is to underestimate or neglect some pragmatic features that can make an important difference with this basic model and then may lead to tough cases. Some of these features can appear through the answers to questions such as: "Who are the people concerned by the rationale?" "Do they already have any opinions about the proposition at stake?" "Did they make them public?" "Can they reply?" "What happens when other people intervene or take a stand in the exchange?" "What happens when people change their minds about the truth of the proposition that is at stake?"

A virtue of the normative approach of pragma-dialectics is that it takes into account some preliminary questions of this kind. The participants to a pragma-dialectical debate are supposed to make their views explicit during the first normal step of 
the exchange: the "confrontation stage". Depending upon its result, there will be an argument or not, because pragma-dialectics holds that a necessary condition of having an argument is an explicit difference of opinion. Unfortunately, you sometimes have no answer, or not all the answers, to these questions. Tough cases are also likely to appear because some actual situations are closer to polylogues than to paradigmatic face-to-face dialogues and raise specific communicational problems (Sylvan 1985, Lewinski \& Aakhus 2014, Lewinski 2014). Yet I will show that, even if all these preliminary questions are answered, the orthodox distinction between argument and explanation is not sufficient to avoid tough cases.

\section{Evidence}

A common view is that a rationale is an argument when the reasons offered are evidential or epistemic: They are "reasons to believe". Harman gives the following definition: " $\mathrm{R}$ is an epistemic reason to believe $\mathrm{P}$ only if the probability of $\mathrm{P}$ given $\mathrm{R}$ is greater than the probability of $P$ given not-R" $(1999, p$. 17). If "believe" sounds too psychological, we could get rid of it and say: " $\mathrm{R}$ is an epistemic reason for $\mathrm{P}$ only if the probability of $\mathrm{P}$ given $\mathrm{R}$ is greater than the probability of $\mathrm{P}$ given not- $\mathrm{R}$ ". Especially in a context of reason-giving involving more than one agent, you can wonder how to interpret this probability. Is it an objective probability? Is it the arguer's opinion about the probability of P? Is it its probability according to an addressee? Or according to a community? (If yes, which one?) Or according to a perfectly rational agent?

A possible interpretation is that this probability refers to a doxastic opinion about the proposition at stake. A doxastic opinion is typically, but non-exclusively, expressed by an indefinite word like "people" or a pronoun like "we", "you" or "they" used in an indefinite way. For example: "We know that there is no life on Mercury". A more moderate doxastic attitude can be expressed by means of "Most people think that..." or "You often say that...". Govier clearly relies on a doxastic opinion to discuss Thomas's tough case: "All natural disasters are comforting because they reaffirm our impotence ..." (1987, p. 170). According to her, this case cannot serve as an explanation because " $\mathrm{few}$ would assent" to the conclusion, and "there is nothing to be explained unless we are antecedently convinced that natural disas- 
ters are comforting". 11 We see "few" against "we".

Govier's decision is not based on the explicit or presumed agreement of an actual or virtual addressee, as in Johnson's case, but on the priority given to a presumed majority over the opinion of "few". What is the scope of this majority? Who are its members? To give privilege to a majority against a minority is a democratic attitude, but as far as the truth of a proposition is concerned, it can be a mistake to rely on the opinion of a majority and doing so can be suspected of committing an ad populum fallacy. If the probability of a proposition is more or less proportional to the rate of people who accept it, the more a majority is short, the more this proposition is likely to be in need of evidential reasons. Some cases are tough, not only because I have no opinion about the truth of the conclusion, but also because no doxastic opinion supports it. In the example of the signal sent by proteins to the detector of the synchrotron, although I acknowledge a rationale but cannot make any decision about its status, I can easily imagine that scientists consider that it is an explanation. Nevertheless, if I am an adept of the orthodox view and am also suspicious of ad verecundiam moves, I should initially check that the conclusion is not controversial. ${ }^{12}$ If I prefer to rely on the authority of a doxastic view, I may find myself in trouble. It is not always so easy to discover what the doxa says. Let us look at Govier's fourth example. ${ }^{13}$ "Cable television today is at a stage where the general exercise of choice is still possible because citizens may still take a hand in shaping cable television's growth and institutions". Keeping in mind that this rationale was written in 1971, was its conclusion true or widely accepted? I am afraid that today "we" have no obvious answer. Even after a dive into historical documents we could have no clear answer. Like Govier, we could then choose to say that it is both an argument and explanation, and in so doing, renounce the exclusivity thesis and save the exhaustivity one. Another option is to renounce the exhaustivity thesis and hold that this rationale is neither an argument nor an explanation.

Another drawback of the doxastic approach is that it is likely to be partial. "We" or "people" are not only often vague terms, but can also be suspected to be both judge and judged. ${ }^{14}$ This is not very important when the topic is notoriously controversial or uncontroversial. In such a case you usually know if you are included or not in "we" or "people". Thus, some cases

11 The italics are mine.

${ }^{12}$ I doubt that many people actually do that.

${ }_{13}$ To be brief, I borrow only part of this long example.

14 This is less obvious with other pronouns like "they" or "you". 
are tough because no doxastic opinion is available, and others because we realize that the conclusion is controversial here, but uncontroversial there, or controversial at this moment, but uncontroversial at that one. It seems arbitrary to favor one side rather than the other.

To avoid the possible bias of a doxastic approach, you can foster the point of view of a single person. Many authors give the precedence to the arguer. ${ }^{15}$ Virtual or actual, the other opinions (doxastic, opinion of an audience or of an addressee) are then discarded or play only an ancillary role. Now, a rationale is an argument if the arguer believes that his reasons are evidential. As McKeon puts it: "If $I$ offer propositions in support of a proposition $\mathrm{P}, I$ am committed to those propositions representing evidential reasons for P" (2013, p. 285). Nevertheless, especially when the virtue of a rationale is intended to be publicly acknowledged, why should the arguer's opinion suffice to decide? Is there any other reason to favor an arguer-centered approach or, more generally, a one person-centered approach, than the concern to preserve a familiar clear-cut distinction between argument and explanation? It seems unlikely that a single person considers a proposition to be true and uncertain at the same time. Someone who puts forward a rationale should know whether her rationale is an explanation or an argument. ${ }^{16}$ But as shown by the case of Pythagoras' theorem, what happens when an opinion held as true by someone is suddenly challenged by another? If, for whatever reason, the supporter of the opinion does not take into account the other's negative attitude (opposition, doubt or ignorance), she will say she explains. Pinto's position seems germane to this view: I explain what is certain for me (and for people who share my opinion). If the arguer is sensitive to negative opinions or doubt, she will say she argues. The distinction would become a matter of psychological slant: skeptics argue, dogmatics explain.

You could try to support the priority of the opinion of the arguer about her rationale on the following grounds, inspired by Grice's view about non-natural meaning (1989, pp 283-303) or Sperber \& Wilson's communicative intention $(1995,2012)$ and roughly summarized in the motto: "Working out what people mean is what defines successful communication". ${ }^{17}$ Therefore, a

${ }^{15}$ I should say the reason-giver, but to avoid this neologism, I will say the arguer, even if the arguer explains.

${ }^{16}$ This is a normative or theoretical view. The trouble students have with the distinction between argument and explanation suggests a factual situation that is rather different.

${ }^{17}$ I owe this objection to a helpful referee, whom I thank. 
correct interpretation of an utterance requires acknowledging that it is of the kind the utterer intended. In our case, the communicative intention would determine the nature of the rationale: argument or explanation. I can grant the premise of this objection but not the conclusion. Communication can be said "successful" in the sense that: (1) the addressee or the analyst understands the context, (2) she understands the utterer's meaning, (3) she acknowledges her intention to explain (or to argue), (4) sometimes, she can acknowledge that the rationale is as strong as the utterer claims it is. However, the addressee may have independent reasons to think that some part of the rationale goes wrong, for instance that a premise or the conclusion is false. Successfully working out what people mean is no reason to grant their opinion about the status of what they do and say. Communication and interpretation can be successful without being consensual or irenic.

An addressee may already believe the conclusion of a rationale put forward by an arguer who also believes it, but wrongly thinks that the addressee does not. If this arguer is Johnsonian and decides on the basis of her own representation of the other's epistemic attitude, she will wrongly decide that her rationale is an argument. Imagine now that a third agent who notoriously disagrees with the conclusion is also involved in the discussion: The Johnsonian arguer would then explain and argue at the same time. Notice that this new tough case for the orthodox distinction is not a consequence of a lack of information about the epistemic conditions of the use of this rationale. It is a consequence of the very definition of argument and explanation.

A third option is to leave anybody free to decide whether a rationale is explanatory or evidential. Granting that the distinction depends only on the status of the conclusion, is it my opinion that matters, or the opinion of one of my virtual or actual interlocutors or audience, or my opinion about their opinion (as in Johnson's case)? Sometimes, an arguer does not believe the conclusion she publicly supports and holds as true. Secretly, she argues, although she publicly claims to explain. This has to happen to lawyers paid to defend an accused of whose guilt they are certain. On the other hand, when the arguer believes the conclusion of her rationale, from her own point of view, she does not argue, but explains. However, an addressee, virtual or not, who would resist the conclusion of this explanation, could rightly say that the utterer does not explain but argues. A generalized individual relativism is on hand; but another consequence is that the 
distinction between argument and explanation is going to be blurred, for if a virtual agreement about the conclusion of a rationale suffices to say that it is an explanation, then any rationale is an explanation, and if a virtual disagreement suffices to say that it is an argument, then any rationale is an argument. This could be seen as an illustration of Protagoras's saying to the effect that, on any topic, two discourses oppose each other. ${ }^{18} \mathrm{Be}$ cause you can always imagine someone doubting the conclusion of any rationale, even Pythagoras's theorem, any rationale is an argument. You don't even need to wait for an actual opponent or sceptic to argue.

We know that explanation-seeking is one of the two paradigmatic situations inspiring the orthodox distinction between argument and explanation. Yet there is at least another paradigmatic situation involving explanation: explanation-giving. This occurs when someone thinks she has an explanation and states it publicly as such, even if everybody around her disagrees, doubts, or does not know. Explanation-giving is quite common in educational contexts, or more generally, when someone expounds a doctrine in which she believes. ${ }^{19}$ For example, Simplico is certain that the sun moves and the earth does not. He is proud to hear his rationalist fellows say that he is a naïve empiricist, and he loves to reply, especially to trendy young mathematicians: "Don't argue, just look!" He explains to one of them, Galilo, that the sun does move, because it turns around the earth. Who could deny the fact that the sun moves in the sky? Just look! Galilo answers: "Of course it moves! You are right Simplico, all our brothers and sisters in God know that. Reasonable beings believe it and even heretics could not deny it. But you know, we would also see it moving if the earth were turning around it. I dare say that it would move even if it did not move by itself". Simplico replies: "Of course! God moves it! In spite of gossip, I knew that you were a good believer, Galilo." Turning to Sacrado, Galilo whispers: "It is terrible to think that no reasonable person would believe us if we were to confess that sometimes we are not absolutely certain that the sun moves."

18 This saying is reported by Diogenes Laertius in the chapter of his Lives and Opinions of Eminent Philosophers devoted to Protagoras. If Protagoras did say something like that, what did he mean exactly? It seems unlikely that he meant that on any topic two discourses actually oppose each other, but rather that two discourses can oppose each other on any topic. This is how I interpret it here.

19 This is not a very new idea. See, for instance, what Aristotle called "didactic dialogues" (not to say "argument") in the second chapter of his Sophistical Refutations. 
Is "the sun turns around the earth" an explanation or an evidential reason for "the sun moves"? This is another tough case. Is the probability of "the sun moves" higher given "the sun turns around the earth" than given "the sun does not turn around the earth"? I do not know. A consequence of an extreme individual relativism about the explanation/argument distinction is that it may fluctuate from person to person and from time to time as soon as an opinion changes or a newcomer gets involved in the game. As foreseen by Hempel, today's explanation may become tomorrow's argument and conversely.

\section{Epistemic asymmetry}

Hamblin writes that in argument: "The conclusion must be less probable a priori than the premises" (1970, p. 240). A similar view is held by Govier: "In the explanation, the explained statement is as certain as the explaining statements and often more certain. In an argument the premises are typically more certain than the conclusion. Thus the relevant beliefs of arguers and explainers and their respective audiences differ very significantly" (1987, p. 162). Unfortunately, she does not explain how she knows they differ. Is it a normative claim? Was there a confrontation stage, as in pragma-dialectics? She goes on: "In an argument certainty moves from the premises to the conclusion, whereas in an explanation it moves from the fact explained to the explanatory hypothesis".

First, certainty without someone who is certain is difficult for me to understand. Even when I use sentences like "it is certain that the murderer was in the room", I presume that "they" are certain, without any clear idea of the reference of "they". It could be the police, the staff of the hotel or whoever, at any rate people who are presumed to be reliable. Who knows? Certainty, too, can be doxastic. Second, we should be careful with the metaphor of certainty moving. When Govier says that certainty moves from the fact explained to the explanatory hypothesis, she seems to have in mind something like the paradigmatic explanation-seeking situation. However, when Simplico explains that the sun moves because it turns around the earth, he does not look for an answer to "Why does the sun move?" He already has it. His certainty has moved and he is now as certain, maybe more certain, that the sun moves around the earth as he is of the observable motion of the sun. His dialogue with Galilo is not explanation-seeking, but explanation-giving. What about Galilo?

He has many independent reasons to think that the earth turns 
around the sun, and this could explain why we see the sun moving in the sky. Today, he is not as certain that the sun actually moves as he was yesterday. The situation is a bit confused for him, because it seems that the sun could move and not move! Is his explanation "the sun moves because the earth turns around it" just an argument, because his certainty moves from his new certainty ("the earth turns around the sun") to the old common statement ("the sun moves") which is now less certain for him? According to Hamblin's requirement, it cannot be an argument, because all doxastic a priori considerations make the conclusion more certain than the premises. Here comes another tough case. Again, the problem is not to doubt the existence of situations where someone or a group considers that the premises of a rationale are more (or less) certain than the conclusion, but the reason to foster this person or group rather than that one, and then to decide whether the rationale is an argument or an explanation.

The asymmetry thesis faces two kinds of difficulties. Both for Hamblin and Govier, it sets a condition on the relative probability of the premises, compared with the conclusion. This says nothing about the certainty of the conclusion. Therefore, the previous discussion and difficulties based on the status of the conclusion are still on the critical agenda. What should we call a rationale whose propositions are all uncertain, but its premises less certain than the conclusion? Does the criterion about the uncertainty of the conclusion have priority over the relative certainty of the premises?

Yet the specific difficulty of the asymmetry thesis comes from this last condition on the relative certainty of premises and conclusion. How do you determine that a set of propositions is more certain than another? Is there any reason to opt for a comparison between average or doxastic probabilities, knowing that they depend on a particular population and are likely to fluctuate? On the other hand, if we turn again to individual attitudes, it is likely that the relative probabilities of premise(s) and conclusion are scattered, except when dominant statistical tendencies confirm that a topic is controversial or uncontroversial. Furthermore, the relative certainty of two propositions may move. Remember that the young Galilo thought that the probability of a motion of the sun was close to certainty and the motion of the earth was just a bold hypothesis, whereas the old Galilo was almost sure that the earth moves and became more careful about the motion of the sun. Even if we can evaluate the relative probabilities that the people concerned by a rationale ascribe to its propositions, the same issue remains: Why should we favor the 
views of this person, or of this group, rather than the views of that other one? Had Galilo lived longer, he could have discovered that both the earth and the sun move.

\section{Speech act}

McKeon's skepticism concerns the products, not the speech acts of explaining and arguing. In some sense, mine concerns the latter. Tough cases are not tough qua rationales, ${ }^{20}$ but as situations of communication. Most of my previous objections are based on difficulties raised by the attempts to base the orthodox distinction on the epistemic attitudes of a single agent or on doxastic attitudes. Thus, my approach is pragmatic, and broadly speaking, dialectical. I have no principled objection to the view that reason-giving is a speech act. Unfortunately, classical speech-act theories are not dialectical in the sense that they are theories of action, not of interaction. They remain speaker-centered, even if they acknowledge perlocutionary effects. Yet they provide interesting insights for our topic. Austin rightly stressed that perlocutionary effects do not always fulfill the goals or intentions of the speaker, who can only do her best and hope that her illocutionary act is successful $^{21}$ (1962, pp. 117-119). Searle insisted, against Grice, that the perlocutionary effect does not depend only on the speaker's intentions, but, at least sometimes, on the conventional meaning of what is said (1969, pp. 42-49). In a tough case like Thomas's examples or my trouble with the rationale about proteins, only a minimal perlocutionary effect seems to be produced, namely the identification of a rationale. Even if the speaker claims to argue (or to explain), the hearer or reader can still take her alleged argument as an explanation, or conversely, her alleged explanation as an argument.

Snoeck-Henkemans's pragma-dialectical analysis remains focused on the speaker. For her, like for Johnson, the status of a rationale depends on the speaker's beliefs and expectations about the addressee: "[A]n argumentation is put forward when the speaker expects that the acceptability of the standpoint is at issue, whereas giving an explanation is pointless when the speaker does not believe that the explained statement has al-

\footnotetext{
${ }^{20}$ I do not deny that some rationales can raise difficulties qua rationales.

21 "The perlocutionary act may be either the achievement of a perlocutionary object (convince, persuade) or the production of a perlocutionary sequel". See chapter IX, pp. 117-118. I suggest that this can be illustrated by: "I already held $p$ to be true; your rationale (which you may have considered as an argument or an explanation) made me understand why $p$ was true."
} 
ready been accepted by the listener as depicting a true state of affairs" 22 (2001, p. 240). How does the speaker know that the statement is accepted or not? In the pragma-dialectical theory, the "confrontation stage" is supposed to make all relevant positions explicit. But as long as there has been no confrontation stage, arguer and listener can have different opinions about the nature of the rationale expressed and may be right, or wrong, about the other's views. Snoeck-Henkemans rightly points out that the arguer's opinion can be guessed by an addressee or an analyst if there are modal terms in the premises or the conclusion. Unfortunately, this is only a clue about the arguer's opinion. If you have to guess, it is likely that there has been no confrontation stage. This confirms that, in this case, the arguer's opinion about the listener's opinion is no more than a guess. In any case, I still see no other reason than tradition or habit to give the authority to decide to the speaker, rather than to the listener.

\section{Conclusion}

I agree with Govier that "the contrast [between argument and explanation] retains its fundamental pedagogical importance", but less because this contrast would be fundamental, than because it shows that the same rationale can be used and interpreted in different ways. In the English-speaking culture, the word "argument" is deeply associated with controversy, whereas "explanation", as in many other cultures, is often closely associated with an inquiry stimulated by something that is (often) held to be uncontroversial. Yet this is not sufficient to claim that the use of any rationale is reducible to these two situations or to the underlying opposition between controversial/uncontroversial points of view. We often claim to explain things that are false or uncertain, and it is quite common that we have no opinion about this or that topic.

My contention is that most of the current approaches to a possible distinction between argument and explanation are on the wrong track or are insufficiently developed. This is suggest-

${ }^{22}$ Snoeck-Henckemans presumes that an extra distinction can be made between argument and explanation: "In explanations only causal relations may be employed at the propositional level, whereas for argumentation there are no such restrictions" (2001, p. 234). I doubt the necessity of the causal requirement. An explanation can be based on geometrical considerations (for instance, symmetry) that it is unusual to see as causal. Yet she could be right that something more than being an answer to a why-question is required for a rationale to be explanatory, but this question goes beyond the methodological commitment made in this paper. 
ed by the various kinds of tough cases faced by a classification of rationales which are supposed to be either explanatory or evidential on the basis of only the epistemic status of their conclusions. Granted that arguments and explanations that answer a why-question belong to the province of reason-giving, all this is a good reason to think that this matter has to be sorted out more judiciously.

\section{References}

Austin, J.L. (1962). How to do things with words. Cambridge, MA: Harvard University Press.

Blair, J.A. (2004). Argument and its uses. Informal Logic 24(2), 137-151.

Dufour, M. (2013). Argument and Explanation in Mathematics. In: Argumentation : Cognition and Community, Proceedings of the $10^{\text {th }}$ Biannual Conference of the Ontario Society for the Study of Argumentation (OSSA), Windsor: University of Windsor, May 22-25, pp 391- 400.

van Fraassen, B.C. (1980). The scientific image. Oxford: Clarendon Press.

Govier, T. (1987). Reasons why arguments and explanations are different. In: Problems in argument analysis and evaluation, pp. 159-176. Dordrecht: Foris Publications.

Grice, P. (1989). Studies in the way of words. Cambridge, MA: Harvard University Press.

Hamblin, C.L. (1970). The concept of argument. In: Fallacies, pp. 224-252. London: Methuen.

Harman, G. (1999). Rationality. In: Reasoning, Meaning and Mind, pp. 9-45. Oxford: Clarendon Press.

Hempel, C.G. (1965). Aspects of scientific explanation. In: Aspects of scientific explanation and other essays, pp. 333-489. New-York: MacMillan, The Free Press.

Johnson, R.H. (2000). Manifest rationality. Mahwah (NJ): Lawrence Erlbaum Associates.

Kitcher, P. (1989). Explanatory unification and the causal structure of the world. In: Scientific Explanation, eds. P. Kitcher and W. Salmon, pp. 410-505. Minneapolis: University of Minnesota Press.

Lewinski, M. and M. Aakhus. (2014). Argumentative polylogues in a dialectical framework: A methodological inquiry. Argumentation 28: 161-185.

McKeon, M.W. (2013). On the rationale for distinguishing arguments from explanation. Argumentation 27: 283-303. 
Pinto, R. (2010). The uses of argument in communicative contexts. Argumentation 24: 227-252.

Potocnik, A. (2011). Explanation and argument. European Journal for Philosophy of Science 1(1): 29-38.

Salmon, W.C. (1978). Why ask "Why?. In: Proceedings and addresses of the American Philosophical Association 51(6): 683-705.

Salmon, W.C. (1984). Explanation and the causal structure of the world. Princeton: Princeton University Press.

Salmon, W.C. (1989). Four decades of scientific explanation. Minneapolis: University of Minnesota Press.

Searle, J.R. (1969). Speech acts. Cambridge: Cambridge University Press.

Sinnott-Armstrong, W. and R. Fogelin (2010). Understanding arguments: An introduction to Informal Logic, $8^{\text {th }}$ ed. Belmont CA: Wadsworth.

Snoeck Henkemans, A.F. (2001). Argumentation, explanation and causality: an exploration of current linguistic approaches to textual relations. In: Text representations: Linguistic and psycholinguistic aspects, eds J. Sanders, J. Schilperoord and W. Spooren, pp. 231-246. Amsterdam: John Benjamins.

Sperber, D. and D. Wilson. 1995. Relevance. Communication \& Cognition, $2^{\text {nd }}$ ed. Oxford: Blackwell.

Sylvan, R. (1985). Introducing polylogue theory. Philosophica 35(1): 89-112.

Thomas, S.N. (1997). Practical reasoning in natural language. Englewood Cliffs (NJ): Prentice Hall. First publication: 1973.

Wilson, D. and Sperber, D. 2012. Meaning and relevance. Cambridge: Cambridge University Press. 